Vol 4 No 2 (2021) 149-160 P-ISSN 2620-295 E-ISSN 2747-0490

DOI: $1047467 /$ elmal.v4i2.532

\title{
Analisis Implementasi Akad Hybrid Contract Murabahah bil Wakalah di Bank BJB Syariah Kc Bogor Jabar
}

\author{
Fitri Nurul Fauziah1, Ahmad Mulyadi Kosim², Santi Lisnawati ${ }^{3}$ \\ 1,2,3Universitas Ibn Khaldun Bogor \\ fitrinurulfauziah98@gmail.com¹, ahmadmulyadi@fai.uika-bogor.ac.id², \\ santilisnawati@gmail.com³
}

\begin{abstract}
Financing is one of the important activities in the banking world because it is the main source of income and is one of the supporting businesses of the bank. Murabahah is a sale and purchase contract in sharia economy where the selling price of the goods is in the form of the cost of goods plus profits and has been agreed upon by both parties. Wakalah is giving or delegating the power of a job to another person as long as it does not violate the syara' law. Hyrid contract is two contracts that are united in one transaction (multi contract). One of the hybrid contracts in Islamic banks is the murabahah bil wakalah contract. Murabahah bil wakalah contract is a combination of two contracts in which the wakalah contract is used before the murabahah sale and purchase contract. The purpose of this study was to analyze how the implementation of the hybrid contract agreement on murabahah bil wakalah at Bank BJB Syariah Bogor Branch. This research uses descriptive qualitative method. The data used comes from primary data in the form of documentation and the results of interviews with staff account officers of Bank BJB Syariah Bogor Branch. The results of this study indicate that in its implementation Bank BJB Syariah Bogor Branch has complied with the DSN-MUI fatwa No.4/DSN-MUI/IV/2000 regarding murabahah. The advantages of murabahah bil wakalah are that it makes it easier for banks to process financing, is more flexible in modern financing needs and is less risky. While the weakness of the murabahah bil wakalah contract is that there is often misuse of funds by customers, such as the purchase of goods that are not in accordance with the RAB that has been agreed upon by the bank and the customer. With this result, Bank BJB Syariah Bogor Branch must continue to be consistent in managing sharia banking products so that the sharia economy can continue to grow and develop.
\end{abstract}

Keywords: Implementation, Hybrid contract, and Murabahah bil wakalah

\section{ABSTRAK}

Pembiayaan merupakan salah satu aktivitas penting dalam dunia perbankan karena sumber pendapatan utama dan menjadi salah satu penunjang usaha bank. Murabahah merupakan akad jual beli dalam ekonomi syariah yang mana harga jual barang tersebut berupa harga pokok barang ditambah keuntungan dan telah disepakati oleh kedua belah pihak. Wakalah adalah memberikan atau melimpahkan kuasa suatu pekerjaan kepada orang lain selama tidak melanggar hukum syara'. Hyrid contract merupakan dua akad yang disatukan dalam satu transaksi (multi akad). Salah satu akad Hybrid contract pada bank syariah adalah akad murabahah bil wakalah. Akad murabahah bil wakalah adalah penggabungan dua akad yang 


\section{Vol 4 No 2 (2021) 149-160 P-ISSN 2620-295 E-ISSN 2747-0490 DOI: $1047467 /$ elmal.v4i2.532}

mana akad wakalah terlebih dahulu digunakan sebelum akad jual beli murabahah. Tujuan dari penelitian ini adalah untuk menganalisis bagaimana implementasi akad hybrid contract pada murabahah bil wakalah di Bank BJB Syariah Cabang Bogor. Penelitian ini menggunakan metode kualitatif deskriptif. Data yang digunakan berasal dari data primer berupa dokumentasi dan hasil wawancara dengan staff account officer Bank BJB Syariah Cabang Bogor. Hasil penelitian ini menunjukkan bahwa dalam implementasinya Bank BJB Syariah Cabang Bogor telah sesuai dengan fatwa DSN-MUI No.4/DSN-MUI/IV/2000 tentang murabahah. Kelebihan dari murabahah bil wakalah yaitu lebih memudahkan bank dalam proses pembiayaan, lebih fleksibel dalam kebutuhan pembiayaan modern dan lebih minim resiko. Sedangkan kelemahan akad murabahah bil wakalah adalah sering terjadi penyalahgunaan dana oleh nasabah seperti pembeliaan barang yang tidak sesuai dengan RAB yang telah disepakati oleh bank dan nasabah. Dengan hasil ini Bank BJB Syariah Cabang Bogor harus terus konsisten dalam pengelolaan produk-produk perbankan syariah agar ekonomi syariah dapat terus tumbuh dan berkembang.

Kata Kunci : Implementasi, Hybrid contract, dan Murabahah bil wakalah

\section{PENDAHULUAN}

Perkembangan lembaga keuangan syariah di Indonesia diawali dengan inspirasi masyarakat Indonesia yang dimana terdapat banyak muslim yang memiliki sebuah alternative sistem perbankan islami (Jaelani,2015). Bank syariah atau yang kata lain dari bank islam merupakan bank yang beroperasi dengan tidak mengandalkan pada bunga, bank yang menjalankan suatu kegiatan usahanya dengan bentuk prinsip syariah.

Menurut peraturan bank indonesia No. 5/7/PBI/2003 tanggal 19 mei 2003, pembiayaan adalah penanaman dana bank syariah baik dalam rupiah maupun valutan asing dalam bentuk pembiayaan, piutang, qardh, surat berharga syariah, penetapan, pentertaan modal, penyertaan modal sementara, komitmen dan kontijensi pada rekening administrative serta sertifikat wadiah bank Indonesia. Di era transaksi keuangan modern yang semakin kompleks, kompleksitas ini semakin nyata, karena diperlukan suatu rancangan akad yang bentuknya tidak hanya tunggal tetapi juga gabungan dari beberapa akad, yang kemudian disebut hybrid contract atau akad ganda. Akad hybrid contract pada bank syariah memang sudah sangat familiar, salah satunya adalah pembiayaan murabahah bil wakalah. Wakalah sendiri memiliki makna pelimpahan kekuasaan oleh satu pihak kepada pihak lain dalam hal-hal yang boleh diwakilkan (DSN-MUI, 2000). Dimana aplikasinya dalam perbankan yaitu: pembiayaan invenstasi/barang modal, pembiayaaan konsumtif dan pembiayaan modal kerja (Satrio dan Wildan, 2016). Dalam perbankan syariah terdapat salah satu akad yang diterapkan yaitu akad murabahah. 


\section{Vol 4 No 2 (2021) 149-160 P-ISSN 2620-295 E-ISSN 2747-0490 DOI: $1047467 /$ elmal.v4i2.532}

Akad murabahah telah diatur dalam fatwa DSN MUI No.III/ DSN/ MUI/ IX/ 2017 tentang akad jual beli murabaha. Murabahah merupakan akad jual beli suatu barang dengan menegaskan harga belinya kepada pembeli dan pembeli membayarnya dengan harga yang lebih sebagai laba (DSN-MUI, 2017). Namun pada praktiknya, murabahah di lembaga keuangan syariah, terindikasi mengalami deviasi dari ketentuan-ketentuan syariah, setidaknya dalam dua hal. Pertama, adanya regulasi yang membatasi LKS untuk tidak terjun langsung dalam sektor ril sehingga tidak mungkin melaksanakan akad murabahah secara murni, yaitu jual beli secara langsung. Kedua, dalam hal pengikatan akad jual beli yang umumnya dilakukan mendahului kepemilikan barang oleh lembaga keuangan syariah. Hal ini jelas telah menyalahi, baik prinsip fiqh muamalah itu sendiri maupun hukum universal, bahwa hak menjual merupakan hak turunan dari kepemilikan. Ketiga, dalam pembiayaan murabahah terdapat praktik pencairan dana pembiayaan ke rekening nasabah yang selanjutnya nasabah diminta untuk melakukan pembayaran kepada supplier.

Para pakar teori perbankan Islam mengemukakan bahwa perbankan Islam lebih berdasarkan bagi hasil atau pembagian untung rugi, tidak berdasarkan bunga. Namun demikian, bank-bank Islam dalam prakteknya sejak awal meyakini bahwa perbankan yang berdasarkan PLS (Profit dan Loss Sharing) sulit untuk dilaksanakan karena sifatnya sangat riskan dan tidak pasti. Bank-bank Islam pada umumnya menggunakan murabahah sebagai metode utama pembiayaan, yang merupakan hampir 75\% dari asetnya. Lembaga keuangan syariah khusunya perbankan syariah akan dapat berkembang dengan baik apabila berorientasi pada demand masyarakat. Dengan bermodalkan UU dan nilai-nilai moral. Perbankan syariah harus mampu membuktikan bahwa keberadaannya mampu melayani kebutuhan masyarakat.

Di era transaksi keuangan modern yang semakin kompleks, kompleksitas ini semakin nyata, karena diperlukan suatu rancangan akad yang bentuknya tidak hanya tunggal tetapi juga gabungan dari beberapa akad, yang kemudian disebut hybrid contract atau akad ganda. Akad hybrid contract pada bank syariah memang sudah sangat familiar, hal ini dikarenakan banyak produk keuangan mikro bank syariah menggunakan dua akad atau lebih dalam bertransaksi, salah satunya adalah pembiayaan murabahah bil wakalah. Wakalah sendiri memiliki makna pelimpahan kekuasaan oleh satu pihak kepada pihak lain dalam hal-hal yang boleh diwakilkan (DSN-MUI, 2000). Dasar hukum akad wakalah telah di atur dalam fatwa DSN MUI No. 10/DSNMUI/IV2000.

Menurut teori pengimplementasikan murabahah bil wakalah pada bank syariah yaitu barang secara prinsip harus menjadi milik bank terlebih dahulu sehingga akad pertama yang harus digunakan adalah akad wakalah, setelah akad wakalah berakhir 


\section{Vol 4 No 2 (2021) 149-160 P-ISSN 2620-295 E-ISSN 2747-0490 DOI: $1047467 /$ elmal.v4i2.532}

baru kemudian menggunakan akad murabahah. Dari beberapa produk pembiayaan, murabahah merupakan produk pembiayaan yang paling sering digunakan, karena akad murabahah dianggap mudah secara operasional dan kepastian keuntungan yang didapat dari transaksi tersebut. Terdapat beberapa perbankan yang mengaplikasikan sistem hybrid contract murabahah bil wakalah salah satunya adalah Bank BJB Syariah.

Tujuan dari penelitian ini adalah untuk mengetahui bagaimana implementasi pembiayaan dengan akad murabahah bil wakalah di Bank BJB Syariah Cabang Bogor dan menganalisanya apakah sudah sesuai dengan fatwa DSN-MUI N0. 4/DSN/MUI/IV/2000 tentang pembiayaan murabahah. Serta kelebihan dan kekurangan hybrid contract akad murabahah bil wakalah dalam pelaksanaannya di Bank BJB Syariah Cabang Bogor.

\section{TINJAUAN LITERATUR}

\section{Hybrid Contract}

Dalam jurnal Yunus (2019) Hybrid contract dalam bahasa Indonesia yang berarti multi akad. Sedangkan kata multi dalam bahasa Indonesia berarti banyak, lebih dari satu, lebih dari dua atau berlipat ganda. hyrid contract adalah dua akad yang disatukan dalam satu transaksi (multi akad). Perkembangan ekonomi saat ini menuntut lembaga keuangan khususnya syariah untuk menerapkan akad hybrid contract karena akad ini dinilai lebih praktis dan efisien dimana nasabah dapat menggunakan dua akad dalam satu transaksi.

\section{Murabahah}

Secara bahasa murabahah berasal dari kata ribhun (keuntungan). Sedangkan secara istilah adalah suatu akad transaksi jual beli dimana bank akan menyebutkan harga jual dan jangka waktu pembayaran angsuran yang telah disepakati sehingga dalam hal ini bank bertindak sebagai penjual, sementara nasabah sebagai pembeli. Menurut Lukman (2017) Murabahah adalah akad jual beli yang disepakati antara Bank Syariah dengan nasabah, dimana Bank menyediakan pembiayaan untuk pembelian barang yang dibutuhkan nasabah, yang nantinya akan dibayar kembali barang tersebut sebesar harga jual bank ( harga pokok + margin keuntungan ) pada waktu kesepakatan yang telah ditentukan. 


\section{Vol 4 No 2 (2021) 149-160 P-ISSN 2620-295 E-ISSN 2747-0490 DOI: $1047467 /$ elmal.v4i2.532}

\section{Wakalah}

Wakalah secara bahasa berasal dari kata wazan wakala - yakilu - waklan yang berarti menyerahkan atau mewakilkan urusan, sedangkan secara istilah wakalah adalah pekerjaan yang diwakilkan, Al- wakalah juga berarti penyerahan (al - Tafwidh) dan pemeliharaan (al- Hifdh) suatu barang kepada orang yang dipercaya untuk diserahkan kepada pihak yang telah ditentukan. Menurut Antonio (dalam skripsi milik Satriana, 2020) wakalah dalam arti harfiah adalah menjaga, menahan, atau penerapan keahlian atau perbaikan atas nama orang lain, menunjuk seseorang untuk mengambil alih atas suatu hal juga untuk mendelegasikan tugas apapun ke orang lain.

\section{Murabahah bil Wakalah}

Murabahah bil wakalah adalah jual beli dengan sistem perwakilan (wakalah). Dimana jual beli dengan sistem ini pihak lembaga keuangan mewakilkan pembeliannnya kepada nasabah, dengan demikian akad pertama adalah akad wakalah setelah akad wakalah berakhir yang ditandai dengan penyerahan barang dari nasabah ke lembaga keuangan syariah kemudian pihak lembaga memberikan akad murabahah (Permana, 2017). Akad murabahah bil wakalah juga merupakan akad jual beli dimana lembaga keuangan syariah mewakilkan pembelian produk kepada nasabah kemudian setelah produk tesrsebut di dapatkan oleh nasabah kemudian nasabah memberikannya kepada pihak lembaga keuangan syariah. Setelah barang tersebut di miliki pihak lembaga dan harga dari barang tersebut jelas maka pihak lembaga menentukan margin yang didapatkan serta jangka waktu pengembalian yang akan disepakti oleh pihak lembaga keuangan syariah dan nasabah (Nurhikma, 2019). Bentuk akad ini dilarang dalam syariah. Contohnya menggabungkan akad jual beli dan pinjaman ( bai wal salaf) . Contoh lain, mengabungkan qardh wal ijarah dalam satu akad. kedua contoh tersebut dilarang oleh nash (dalil) syariah, qardh dengan janji hadiah (hibah), akad salaf dengan jual beli (Ariyanti 2016).

\section{METODE PENELITIAN}

\section{Jenis Penelitian dan Sumber Data}

Penelitian ini menggunakan metode kualitatif deskriptif. Metode kualitatif deskriptif adalah metode pengolahan data dengan cara menganalisa faktor-faktor yang berkaitan dengan objek penelitian dengan penyajian data secara lebih mendalam terhadap objek penelitian (Prabowo \& Heriyanto, 2013). Penelitian ini dinilai cocok dengan metode kualitatif deskriptif karena digunakan untuk mengamati Analisis Implementasi akad Hybrid Contract pada Murabahah Bil Wakalah di bank BJB Syariah. 


\section{Vol 4 No 2 (2021) 149-160 P-ISSN 2620-295 E-ISSN 2747-0490 DOI: $1047467 /$ elmal.v4i2.532}

\section{Data dan Sumber Data}

Data yang digunakan dalam penelitian ini adalah data primer. Data primer yaitu data yang belum tersedia dan untuk memperoleh data tersebut peneliti harus menggunakan beberapa instrument penelitian dan istrument yang digunakan dalam penelitian ini dari data primer yaitu wawancara dengan satu narasumber (Tanjung \& Devi, 2013). Pada penelitian ini sumber data yang diperoleh melalui hasil wawancara dengan salah satu staff Account Officer konsumer Bank BJB syariah cabang Bogor.

\section{Teknik Analisis Data}

Teknik analisis yang digunakan adalah : 1). Wawancara adalah pengumpulan data dengan bertanya jawab langsung kepada responden. 2). Dokumentasi merupakan salah satu teknik pengumpulan data yang dilakukan untuk mendapatkan informasi dokumen-dokumen yang dibutuhkan sebagai bentuk bukti pertanggung jawaban dalam penelitian ini. Dokumentasi pada penelitian ini berupa foto hasil wawancara peneliti dengan narasumber melalui pesan dan gambaran umum mengenai Bank BJB Syariah.

\section{Pemeriksa Keabsahan Data}

Pemeriksa keabsahan data penelitian kualitatif meliputi: pertama Kredibilitas (Credibility), kedua Pengujian (Dependability), ketiga Komfirmasi (Confirmability)

\section{Prosedur Analisis Data}

penelitian ini menggunakan Pengumpulan data dilakukan oleh peneliti melalui hasil wawancara dan dokumentasi berupa data nasabah yang menggunakan akad murabahah bil wakalah, kemudian reduksi data Setelah semua data dikumpulkan pada tahap sebelumnya, langkah selanjutnya peneliti akan mereduksi data yang telah dikumpulkan dengan cara menggolongkan, membuang yang tidak perlu dan mengorganisasi data sedemikian rupa sehingga dapat ditarik kesimpulan, setelah itu melakukan penyajian data sehingga peneliti dapat mendeskripsikan hasil penelitian yang telah di kumpulkan agar mudah dipahami dengan baik dan dapat ditarik kesimpulannya, dan yang terakhir kesimpulan merupakan tahapan akhir dalam penelitian ini. Setelah melakukan penyajian data dari data yang dikumpulkan sebelumnya, data kemudian di analisis untuk nantinya dapat ditarik kesimpulan.

\section{HASIL DAN PEMBAHASAN}

Penggunaan hybrid contract saat ini pada setiap lembaga keuangan khususnya di perbankan syariah sangat berperan penting. Penggunaan multi akad dinilai lebih fleksibel dan efisien mengikuti kemajuan pembiayaan modernisasi yang membutuhkan lebih dari satu akad dalam satu transaksi. Akad hybrid contract di Bank BJB Syariah yang sering digunakan adalah murabahah bil wakalah. Pembiayaan konsumtif dengan 


\section{Vol 4 No 2 (2021) 149-160 P-ISSN 2620-295 E-ISSN 2747-0490 DOI: $1047467 /$ elmal.v4i2.532}

menggunakan akad wakalah dinilai lebih mudah karena bank dapat mewakilkan pembelian barang kepada nasabah untuk dibelikan barang yang dibutuhkan nasabah.

Berdasakan hasil temuan penelitian yang dilakukan peneliti di Bank BJB Syariah Cabang Bogor, pada implementasi akad hybrid contract murabahah bil wakalah di Bank BJB Syariah Cabang Bogor akad pertama yang digunakan yaitu akad wakalah setelah itu akad murabahah walaupun Bank BJB Syariah belum memiliki barang yang dibutuhkan oleh nasabah akan tetapi Bank BJB Syariah memiliki dana untuk pembelian barang yang dibutuhkan nasabah sesuai dengan kesepakatan jual beli murabahah tentang barang atau objek yang telah disepakati. Kemudian pembelian barang oleh bank diwakilkan kepada nasabah menggunakan akad wakalah. Setelah nasabah membeli barang yang dibutuhkan Bank BJB Syariah meminta riwayat bukti penggunaan dana (kwitansi) untuk disesuaikan dengan RAB pada saat perjanjian kesepakatan akad murabahah. Berdasarkan dengan teori yang merujuk kepada Fatwa DSN-MUI Nomor: 04/DSNMUI/IV/2000, tentang akad murabahah pada ketetapan pertama ayat kesembilan menyatakan bahwa: "Jika Bank hendak mewakilkan kepada nasabah untuk membeli barang dari pihak ketiga, akad jual beli murabahah harus dilakukan setelah barang secara prinsip menjadi milik Bank (Fatwa DSN nomor: 04/DSN-MUI/IV/2000). Dapat diartikan bahwa akad wakalah yang diterapkan oleh bank kepada nasabah harus dilakukan ketika barang yang diperjual belikan secara prinsip menjadi milik bank. Setelah bank memiliki barang tersebut maka akad wakalah berakhir dilanjutkan akad jual beli murabahah dengan menjelaskan harga pokok barang ditambah margin keuntungan pada awal kesepakatan perjanjian akad.

Jika dilihat dari pelaksanaan pembiayaan murabahah bil wakalah pada Bank BJB Syariah Cabang Bogor sudah sesuai dengan fatwa DSN-MUI Nomor: 04/DSNMUI/IV/2000 tentang murabahah karena Bank BJB Syariah mendahulukan akad wakalah kemudian dilanjutkan dengan akad jual beli murabahah. Secara syariah bank diperbolehkan memberi kuasa kepada nasabah melalui akad wakalah untuk bertindak sebagai wakil dari bank untuk membeli barang yang dibutuhkan sesuai perjanjian kesepakatan akad murabahah yang disetujui oleh bank. Berdasarkan fatwa DSN-MUI Nomor: 4/DSN-MUI/IV/2000 tentang wakalah pembelian yang diwakilkan oleh pihak nasabah maka nasabah harus menyerahkan bukti pembelian atau kwitansi barang atau jasa yang dibeli oleh nasabah kepada pihak bank. Dalam implementasi di Bank BJB Syariah sudah sesuai dengan Fatwa DSN-MUI Nomor : 4/DSN-MUI/IV/2000 tentang wakalah karena Bank BJB Syariah meminta bukti pembeliaan atau kwitansi kepada nasabah untuk disesuaikan dengan RAB yang telah disepakati dengan bank.

Setiap produk pembiayaan bank pasti terdapat kelebihan dan kekurangan. Pada Bank BJB Syariah Cabang Bogor peran akad murabahah bil wakalah sangat penting 


\section{Vol 4 No 2 (2021) 149-160 P-ISSN 2620-295 E-ISSN 2747-0490 DOI: $1047467 /$ elmal.v4i2.532}

karena memiliki banyak kelebihan seperti memudahkan bank dalam proses pembiayaan, lebih fleksibel dalam kebutuhan pembiayaan saat ini yang membutuhkan dua akad dalam satu transaksi. Sedangkan kelemahan yang sering terjadi pada akad murabahah bil wakalah di Bank BJB Syariah Cabang Bogor adalah sering terjadi penyalahgunaan dana oleh nasabah seperti pembeliaan barang yang tidak sesuai dengan RAB yang telah disepakati oleh bank dan nasabah

\section{KESIMPULAN}

Berdasarkan hasil analisis implementasi akad hybrid contract pada murabahah bil wakalah di Bank BJB Syariah Cabang Bogor maka dapat disimpulkan bahwa :

1. Implementasi akad hybrid contract pada murabahah bil wakalah di Bank BJB Syariah Cabang Bogor ditinjau dari Fatwa DSN-MUI Nomor. 04/DSN-MUI/IV/2000 tentang murabahah bait pertama point kesembilan yang menjelaskan bahwa "Jika bank hendak mewakilkan kepada nasabah untuk membeli barang dari pihak ketiga, akad jual beli murabahah harus dilakukan setelah barang, secara prinsip menjadi milik Bank". Dalam implementasinya Bank BJB Syariah Cabang Bogor melalui pembiayaan konsumtif menggunakan akad murabahah bil wakalah sudah sesuai dengan Fatwa DSN-MUI Nomor. 04/DSN-MUI/IV/2000. Karena akad pertama yang digunakan Bank BJB Syariah Cabang Bogor adalah akad wakalah, setelah akad wakalah berakhir kemudian dilanjutkan dengan akad jual beli murabahah.

2. Kelebihan dan kekurangan dalam pembiayaan murabahah bil wakalah di Bank BJB Syariah, kelebihan pembiayaan murabahah bil wakalah yaitu memudahkan bank dalam proses pembiayaan, lebih fleksibel dalam kebutuhan pembiayaan saat ini yang membutuhkan dua akad dalam satu transaksi dan lebih minim resiko. Sedangkan kelemahan yang sering terjadi pada akad murabahah bil wakalah di Bank BJB Syariah Cabang Bogor adalah sering terjadi penyalahgunaan dana oleh nasabah seperti pembeliaan barang yang tidak sesuai dengan RAB yang telah disepakati oleh bank dan nasabah.

\section{DAFTAR PUSTAKA}

Abdulahana, M. (2014). KAEDAH-KAEDAH KEABSAHAN MULTI AKAD HYBRID CONTRACT . (hal, 47-49).

Abdurrahman, H. (2016). Rapor Merah Bank Syariah. Cetakan ke 4. Bogor: Al Azhar press. 


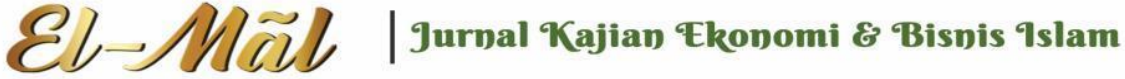

\section{Vol 4 No 2 (2021) 149-160 P-ISSN 2620-295 E-ISSN 2747-0490 DOI: $1047467 /$ elmal.v4i2.532}

Al Hadi, Abu Azam. (2017). FIKIH MUAMALAH KONTEMPORER. (hlm, 54). Depok : PT. Raja Grafindo Persada.

Amar, F. (2020). Implementasi Murabahah Sebagai Alternatif Akad Dalam Pembiayaan Usaha Di Bank BJB Syariah KC Ciputat. (Skripsi, Fakultas Dakwah dan Ilmu Komunikasi Universitas Islam Negri Syarif Hidayatullah, Jakarta)

Anshori, A. G. (2010). Lembaga Keuangan Syariah. Yogyakarta: Universty Press.

Antoni, Muhammad, S. (2010). Bank Syariah Dari Teori Ke Praktik. Jakarta : Gema Insani.

Antonio, Muhammad, S. (1999). BANK SYARIAH BAGI BANKIR DAN PRAKTISI KEUANGAN. Cetakan I . Bogor : Tazkia Institute.

Basyir, A. A. (2000). Asas-Asas Hukum Muamalat (Hukum Perdata Islam. Yogyakarta : Penerbit UII press.

Calista, D. A. (2021). Implementasi Fatwa DSN-MUI VI Tahun 2000 Tentang Akad Murabahah pada Pembiayaan Pemilikan Rumah (PPR) IB Maslahah (Studi kasus di Bank BJB Syariah KC Serang ). (Doctoral dissertation, UIN SMH Banten).

Hakim, L., \& Anwar, A. (2017). Pembiayaan Murabahah Pada Perbankan Syariah dalam Prespektif Hukum di Indonesia. Al- Urban : Jurnal Ekonomi Syariah dan Filantropi islam. 1(2), 212-223. https://journal. Uhamka.ac.id/index.php/alurban/article/view/1026.

Hidayat, Rahmat (2014). Efisiensi Perbankan Syariah : Teori dan Praktik. Bekasi : Gramata Publishing.

Imrani, Abdullah bin Ahmad Abdullah (2006). Al-Uqud Al-Maaliyah Al-Murakabhah Studi Fiqih Ta'shiliah Wa Tathbiqiyyah. Riyad : Dar Kunuz Elshabelia An Nasr wa Tausi'.

Isfandiar, A. A. (2014). Analisis Fiqh Muamalah tentang Hybrid Contract Model dan Penerapannya pada Lemabag Keuangan Syariah. Jurnal penelitian, 10(2). http://e-journal.iainpekalongan.ac.id/index.php/Penelitian/article /view/361>. (Tanggal diakses : 13 Juli 2021).

Iska, Syukri. (2012). Sistem Perbankan Syariah di Indonesia dalam Presfektif Fikih Ekonomi. Yogyakarta Fajar Media Press. 


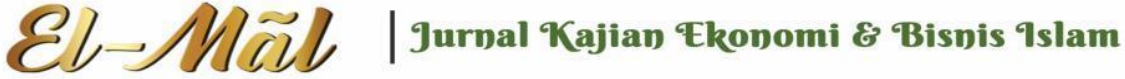

\section{Vol 4 No 2 (2021) 149-160 P-ISSN 2620-295 E-ISSN 2747-0490 DOI: $1047467 /$ elmal.v4i2.532}

Jaelani, Ahmad. (2015). ANALISIS TERHADAP MEKANISME PEMBIAYAAN MIKRO DENGAN AKAD MURABAHAH DI BANK SYARIAH MANDIRI KANTOR CABANG PEMBANTU SEMARANG TIMUR. Skripsi, Fakultas Ekonomi Dan Bisnis Islam Universitas Islam Negri Walisongo, Semarang.

Jamaludin, I. (2017). Kontrak Hybrid Contract Menurut Hukum Ekonomi Syariah. Jurnal Studi Ekonomi. 1 (1), 45-56. http://doi.org/10.32506/joes.vv1i1.7 ( diakses tanggal 13 Juli 2021).

Karim, Adiwarman. A. (2014). Bank Islam Analisis Fiqih dan Keuanggan (edisi empat). Jakarta : PT. Raja Grafindo Persada.

Muhammad. (2005). MANAJEMEN BANK SYAR'IAH (Edisi revisi). Sekolah Tinggi Ilmu Managemen Yayasan Keluarga Pahlawan Negara (STIM YKPN) Yogyakarta.

Muthaher, Osmad. (2012). Akutansi Perbankan Syariah. Yogyakarta : Graha Ilmu.

Najamuddin, H., \& Lc, M.A. (2013). AL-'UQUD AL-MURAKKABAH DALAM PERSPEKTIF EKONOMI SYARIAH. Jurnal Syariah, Vol. 2, No. 2.

Nawawi, Ismail. (2017). Fikih Muamalah Klasik dan Konterporer. Bogor : Ghalia Indonesia.

Nurhikma, N. (2019). IMPLEMENTASI HYBRID CONTRACT PADA PEMBIAYAANMURABAHAH BIL WAKALAH DI BNI SYARI'AH CABANG MAKASAR. (Doctoral dissertation, IAIN Parepare).

Permana, A. A (2017). Analisis pembiayaan murabahah bil wakalah dalam meningkatkan produktifitas dan kesejahteraan nasabah di UJKS KSU Jabal Rahmah Sidoarjo (Doctoral dissertation, UIN Sunan Ampel Surabaya).

Prabowo, A., \& Heriyanto, H. (2013). ANALISIS PEMANFAATAN BUKU ELEKTRONIK (EBOOK) OLEH PEMUSTAKA DI PERPUSTAKAAN SMA NEGERI 1 SEMARANG. Jurnal Ilmu Perpustakaan, 2(2), 152-161.

Putut, G. (2020). PENERAPAN MULTI AKAD (HYBRID CONTRACT) MURABAHAH BIL WAKALAH DITINJAU DARI FATWA DSN-MUI ( Kajian Pada Bank Syariah Mandiri KCP Bima ) (Doctoral dissertation, Universitas Muhammadiyah Malang). 


\section{Vol 4 No 2 (2021) 149-160 P-ISSN 2620-295 E-ISSN 2747-0490 DOI: 1047467/elmal.v4i2.532}

Rahmawati, I. (2019). Pelaksanaan Pembiayaan Multijasa dengan Akad Murabahah pada Produk Pembiayaan Kesejahteraan Pegawai (PKP) di Bank BJB Syariah KCP Subang. (Doctoral dissertation, UIN Sunan Gunung Djati Bandung).

Rozalinda., Fikih ekonomi Syariah : Prinsip dan Implementasinya pada Sektor Keuangan Syariah. Jakarta: PT. Raja Grafindo Persada.

Saeed, Abdullah. (2004). BANK ISLAM DAN BUNGA. (hlm, 136-140). Yogyakarta: Pustaka Pelajar.

Saefuddin, Aep. (2019), AKAD MURABAHAH BIL WAKALAH MENURUT HUKUM EKONOMI SYARIAH DAN FATWA DSN MUI SERTA PENERAPANNYA PADA LEMBAGA KEUANGAN SYARIAH. (Masters thesis, UIN Sunan Gunung Djati Bandung).

Sari, P. N. (2020). ANALISIS PENERAPAN HYBRID CONTRACT DALAM PRODUK PEMBIAYAAN KEPEMILIKAN RUMAH (GRIYA) PADA BANK SYARIAH MANDIRI KCP ULEE KARENG KOTA BANDA ACEH (Doctoral dissertation, UIN AR-RANIRY).

Satriana, D. (2021). Pelaksanaan Pembiayaaan Murabahah Bil Wakalah pada Bank Syariah Mandiri KCP Bukittinggi.

Satrio, A. S. W. (2016). PENERAPAN AKAD MURABAHAH PADA PRODUK PEMBIAYAAN MIKRO DI BRI SYARIAH KCP MAJAPAHIT SEMARANG. (Doctoral dissertation, UIN Walisongo).

Semmawi, R. (2010). Urgensi Akad dalam Hukum Ekonomi islam. Jurnal Ilmiah AlSyir'ah, 8.2.

Suwendra, I.W. (2018). Metodologi Penelitian Kualitatif dalam Ilmu Sosial, Pendidikan, Kebudayaan,dan Keagamaan. Bandung: Nilacakra.

Tanjung, H. \& Devi, A. (2018). Metodologi Penelitian Ekonomi Islam: Edisi ke 2. Bekasi: Gramata Publishing.

Tanjung, Hendri \& Devi, Abrista. (2013). METODOLOGI PENELITIAN EKONOMI ISLAM. Jakarta: Gramata Publishing

Yosi Aryanti. (2016). MULTI AKAD ( $A L-U Q U D$ AL-MURAKKABAH ) DI PERBANKAN SYARIAH PERSPEKTIF FIQH MUAMALAH. Jurnal Ilmiah Syariah. Vol. 15, No. 2 (diakses tanggal 13 Juli 2021),178. 


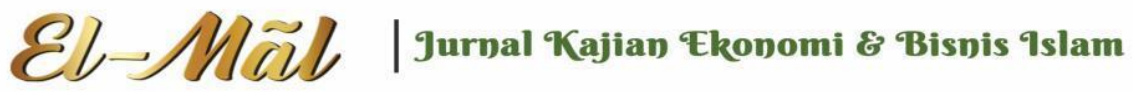

\section{Vol 4 No 2 (2021) 149-160 P-ISSN 2620-295 E-ISSN 2747-0490 DOI: $1047467 /$ elmal.v4i2.532}

Yunus, M. (2019). HYBRID CONTRACT (MULTI AKAD) DAN IMPLEMENTASINYA DI PERBANKAN SYARIAH. Tahkim, 2(1).

Yusmad, M. A. (2018). ASPEK HUKUM PERBANKAN SYARIAH DARI TEORI KE PRAKTIK (Edisi Pertama). Cetakan kedua. Yogyakarta : Deepublish.

"Fatwa DSN-MUI No: 04/DSN-MUI/IV/2000 tentang Murabahah". www.dsnmui.or.id diakses tanggal 30 Juni 2021.

"Fatwa DSN-MUI No: 13/DSN-MUI/IV/2000 tentang Wakalah". www.dsnmui.or.id diakses tanggal 30 Juni 2021.

"Hybrid Contract dalam Keuangan Syariah". www.iaei-pusat.org diakses tanggal 30 Juni 2021.

"Profil Bank BJB Syariah, Produk-produk dan Jasa Bank BJB Syariah Cabang Bogor". www.bjbsyariah.co.id diakses tanggal 30 Juni 2021. 